\section{Getting What You Pay For: Finding Value in Cancer Care}

\author{
Margaret Tempero, $\mathrm{MD}$, is on vacation. \\ Please enjoy this "Oncology Watch" from September 2014.
}

Unless you live on another planet, you know that the cost of healthcare is going off the charts-and the cost of cancer care is a major contributor. Cancer treatments currently cost the United States more than $\$ 127$ billion each year, and that amount is projected to increase $27 \%$ from 2010 to 2020 as our population ages and more treatable cancers are diagnosed. Why drugs cost so much and why we can't change that will be the subject of another editorial.

In discussing and assessing cost, we are increasingly introducing the term value, but value is a bit hard to define. I like Warren Buffet's definition, "Price is what you pay; value is what you get." And certainly, "what you get" is subject to interpretation. Setting matters a lot. A bowl of rice could save the life of a starving man, but a bowl of rice at a Chinese banquet is almost inconsequential. Yet, it's the same bowl of rice. In one context, the value is high; in the other, it's marginal.

We can look at healthcare the same way. Gilead Sciences has a new drug for hepatitis C, sofosbuvir. It seems to be pretty effective in clearing viral load, and the estimated cost of a course of treatment is $\$ 84,000$. If I had hepatitis $\mathrm{C}$ and the drug worked for me, my risk of developing chronic liver disease, needing a possible liver transplant, and developing hepatocellular cancer could be avoided. That certainly seems like high value. On the other hand, a course of ipilimumab for treating metastatic malignant melanoma costs about $\$ 120,000$. If I had metastatic malignant melanoma and this drug worked for me, I would live longer. But I might have complications from the drug, and I would still probably die of the disease. So clearly the drug has value, but is it worth the cost?

In reality, I don't have either of these disorders, so I can afford to be objective. I could buy into economic models that assess benefits according to chance for cure or prolongation of life, accounting for the cost of complications balanced by the benefits of continued productivity. But if I did have metastatic malignant melanoma, my assessment of benefit might be very different. I might hope that prolonging my life for a even short time would open doors for new options that could prolong it even further. I would undoubtedly have goals_-don't we all? We want to dance at our children's weddings, meet and teach our grandchildren, and watch endless sunsets with the people we love. How do you assign value to that?

As professionals, we are increasingly being asked to attribute value to the cost of interventions. I do think we have a responsibility to do this, and we will need tools such as weighted economic models for cost and benefit. But I also think this is a societal issue and that the public needs to weigh-in as well. We can't impose our concept of value until we understand the health advocate's perception and interpretation of the same thing. Value is clearly in the eye of the beholder. And like most things, it will take a lot of care and thought to get this right.

What do you think? Please e-mail correspondence (include contact information) to JNCCN@nccn.org or log into www.editiorialmanager.com/JNCCN to submit a Letter to the Editor.

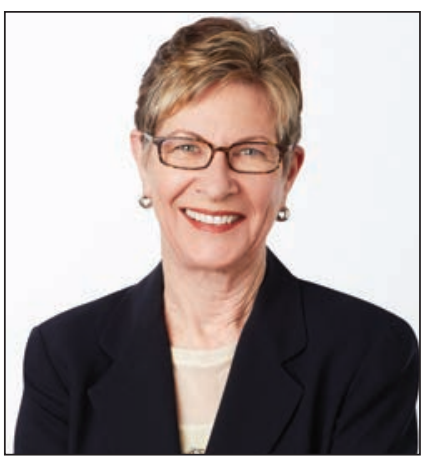

Margaret Tempero, MD

Margaret Tempero, MD, is a Professor of Medicine and Director of the UCSF Pancreas Center and Editor-In-Chief of JNCCN. Her research career has focused on pancreatic ductal adenocarcinoma, especially in the area of investigational therapeutics. Dr. Tempero has served on the ASCO Board of Directors and as ASCO President. She currently serves on the ASCO Conquer Cancer Foundation Board. She codirected the AACR/ASCO Methods in Clinical Cancer Research and taught this course and similar courses in Europe and Australia. She was founding Chair of the $\mathrm{NCl}$ Clinical Oncology Study Section and served as a member and Chair of the NCl Board of Scientific Counselors Subcommittee $A$. She is a member of the Scientific Steering Committee and Chair of the Clinical and Translational Study Section for the Cancer Prevention \& Research Institute of Texas. She is or has been on the Scientific Advisory Boards of the Lustgarten Foundation, the Pancreatic Cancer Action Network, the $V$ Foundation, The Alberta Canada Cancer Board, and the EORTC. She served as a member of the Oncology Drug Advisory Committee for the FDA. She has served as Deputy Director and Interim Director for the UNMC Eppley Cancer Center. She is Chief Emeritus of the Division of Medical Oncology at UCSF and served as the founding Deputy Director and Director of Research Programs at the UCSF Helen Diller Family Comprehensive Cancer Center.

doi: $10.6004 /$ jnccn.2018.0077

The ideas and viewpoints expressed in this editorial are those of the author and do not necessarily represent any policy, position, or program of NCCN. 